\title{
PEDRO HENRIQUEZ UREÑA HUMANISTA E HISPANISTA
}

Pedro Pablo Barnola

Con ocasión de cumplirse treinta años del fallecimiento del ilustre hombre de letras dominicano.

Hay una deuda de gratitud que estamos en el deber de pagarle al siempre recordado maestro Pedro Henríquez Ureña. Y estas líneas quieren, si no satisfacerla en absoluto, porque es difícil, al menos dejar alguna constancia de que tenemos a honra reconocernos entre sus deudores.

Quienes hace cuarenta o más años transitábamos el gustoso pero también arduo camino de la docencia media y superior en letras, nunca olvidaremos los tropiezos y desvelos que nos causaba, a menudo, la falta de la necesaria información bibliográfica. Concretamente, los programas que debíamos de cubrir en materia de cultura literaria hispanoamericana, por muy reducidos que estuviesen a lo más general de los temas y a sólo los autores de mayor significación, requerían de fuentes de estudio adecuadas a una decente preparación de las clases. No es que hubiese carencia absoluta de aquellos libros; pero sí no sobraban. Muchas veces tampoco los que obteníamos con paciencia e ingenio nos facilitaban siempre una información tan completa como la deseábamos.

Recordemos, además, otra cosa; por entonces se había en cierto modo agudizado, o al menos se mantenía vivo, uno de los temas de mayor polémica en la enseñanza de la historia y en la de la literatura, así como en todo lo concerniente -en generala la cultura hispanoamericana colonial. Ese tema se presentaba 
como la negación, a rajatablas, de la existencia de dicha cultura. Era una impugnación, a veces hasta virulenta, que trataba de desvirtuar o de minimizar el valor de tantos y tan diversos hechos que nos gritaban que sí había habido una cultura durante los siglos coloniales hispanoamericanos.

Hasta entonces se tomaban casi como dogma de fe las interpretaciones y juicios tenazmente negativos que historiadores del continente. en general. habían hecho al respecto. La llamada "leyenda negra" campeaba a sus anchas, sobre todo en los escritos de los autores empollados al calor de las doctrinas positivistas, quienes a su vez recogían la herencia de los historiadores anteriores, más cercanos a la época de la emancipación. tan cargada ésta - explicablemente-de sentimientos y de reacción hondamente antihispánicos.

Pero el tiempo, gran depurador y catalizador de los hechos de la historia, había ido haciendo su labor. Y ya al correr del primer tercio del presente siglo las cosas empezaron a tomar otro rumbo con respecto al asunto que ahora recordamos. Y sin que se pretendiese enfrentar apologéticamente una tesis, la llamada "leyenda dorada", a su antagónica la "leyenda negra", historiadore muy sensatos y buenos críticos fueron poco a poco llamando a la reflexión, y demostrando - a la vez-documetalmente, el caso de otra tesis: la verdadera, que en manera alguna podía ignorarse. Sin negar máculas y errores o limitaciones que pudo haber acá o allá en uno u otro momento, en el desarrollo y vida de las instituciones en la Hispanoamérica colonial, no cabía duda de la realidad de un hecho múltiple y muy concreto: la existencia de una cultura general en todo el continente hispánico, la cual -además- en determinados aspectos. lugares y momentos alcanzó muy singular importancia. Derecho y Literatura, Pintura y Música, Metalurgia y Minería, por no citar otras, fueron campos de evidente expresión de aquella cultura que por acá floreció especialmente en los siglos XVII y XVIII.

Adelantado en estas clases de estudios revisionistas de aquel pasado colonial había sido, con carácter casi continental el notable historiador mexicano Carlos Pereyra. Su labor no 
pudo pasar inadvertida y contribuyó sin duda -además- a despertar en los diversos países igual interés por un estudio sereno y objetivo de tema tan apasionante como éste de la búsqueda de nuestras raíces culturales.

Roturado ya eñ terreno y sacados a luz resultados muy positivos, pronto tales resultados fueron entrando al cauce de la enseñanza, aunque al principio no sin algunas resistencias. debidas -más que nada- a desconocimiento de las más recientes fuentes de información.

Fue en tales circunstancias cuando vino a alcanzarnos, todavía muy a tiempo, la labor de un humanista tan bien informado y de tan amplio horizonte cultural como lo era Pedro Henríquez Ureña.

Con años de residencia en México y en España. hubo de serle familiar - tal vez hasta con el propio Carlos Pereyra- el estudio e investigación de los diversos aspectos de nuestra cultura, tomada incluso desde las mismas fuentes o raíces precolombinas, con las que vinieron luego a mezclarse y preponderar los elementos hispánicos durante cuatro siglos largos. Escritor joven. con los arrestos propios de la edad, aunque en circunstancias que pudieron determinarlo a seguir caminos hasta entonces transitados por todos, no se plegó - sin embargoa dichas circunstancias, sino buscó con objetividad y con talento de verdadero estudioso y de competente investigador, la verdad de los hechos, sin prejuicios que en ningún sentido la desfigurasen. Y por eso, pronto, en años aún de madura juventud, su labor se había hecho notar por lo seria y por lo bien escrita. Y no de nuestro continente, sino de España, y de años bien atrás, se oyó por entonces la voz del fino escritor Diez Canedo que dijo -mirando a nuestras letras- que en la nueva generación, Henríquez Ureña era el crítico "de más agudo ingenio y preparación más sólida entre todos los del nuevo continente" . Entre todas sus obras fueron naturalmente dos las de más inmediato y frecuente uso en nuestras labores docentes: la "Historia de la Cultura en la América Hispánica" y "Las Corrientes Literarias en la América Hispánica". Una y otra nos sirvieron a menudo de verdadero Vademecum; sobre todo la segunda. cuya riqueza en 
notas marginales completa casi un tercio del total de sus páginas.

Si mientras vivió fue debidamente apreciada en su justo valor la múltiple obra de cultura de Henríquez Ureña, bien podemos decir que más y más la hemos seguido valorando después de su desaparición - hoy como ayer tan lamentada-pues inevitablemente, como sin querer, hemos de pensar en él cuantas veces - aunque tan a distancia-nuestra modesta actividad tiene relación con materias de las que tan doctamente escribió. Ciertamente esos dos libros que acabamos de mencionar son sólo doctos resúmenes de materia que, con vida más larga, el autor habría podido desarrollar con mayor amplitud y riqueza de datos. $\mathrm{Y}$ sin embargo. tal como nos quedaron, esas obras son de uso provechosísimo como también de agradable lectura. Primeramente, porque en ambas demuestra bien su autor, aquel "don de sintetizar grandes períodos literarios o históricos y de apresar lo esencial en trabajos generalmente breves, cosa que es sólo dable a quien posee una vasta cultura bien asimilada", como lo señaló muy atinadamente el profesor Gómez-Gil ${ }^{2}$. Pero además es de notar que. no obstante esa labor de síntesis tales libros distan mucho de estar escritos con el estilo monótono y seco de quien se limita a recoger y ordenar datos como para una mera información de consulta. Antes bien son libros redactados con lozanía y buen gusto, por lo cual se leen con facilidad e interés. $\mathrm{Su}$ estructura es más de obra literaria que de simple manual didáctico. Porque en ellos su autor, además de conocimientos. ha puesto alma No se ha limitado a divulgar metódicamente lo asimilado de fuentes más amplias o de estudios particulares de cada tema. cuyas referencias complementarias nos da luego en abundantes y eruditas notas. En estas obras Henríquez Ureña hace labor personal de historiador, de crítico, de escritor y de maestro; pero no se olvide que él. anteriormente. en sus primeros escritos se había manifestado con sobrada capacidad y fuerza creadoras y con sensibilidad para obras de inventiva propia y propiamente literarias.

Pero hemos de celebrar que su clara vocación de maestro en ningún caso fue frustrada por otras legítimas apetencias culturales. Más tampoco podrá decirse - en rigor - que dicha vo- 
cación haya frustrado al escritor nato. Pues quien lea a Henríquez Ureña en cualquiera de sus libros, o en la menos llamativa de sus páginas, al punto sentirá que lee a un escritor de verdad; de esos que como un Menéndez Pelayo, o como el gran Alfonso Reyes, tan amigo y cuasipaisano del propio Henríquez Ureña, no importa lo que toquen con su pluma, ni la legítima imagen de eruditos que acompañe a su nombre, sea cual fuera el tema que traten, podemos leerlos siempre con la seguridad de que enontraremos grata y atractiva esa lectura de su bien cortada prosa.

Acierta en alguna manera -creemos-el ya citado historiador literario Gómez-Gil cuando refiriéndose a Henríquez Ureña recuerda, por comparación, a Bello. Por aquello del humanista y erudito de amplia y sólida formación, que consagra buena parte de sus aptitudes al magisterio intelectual, dedicado a la formación de juventudes en las diversas disciplinas necesarias a la cultura americana.

Pudo ser que en el subconsciente ésta su dedicación al alto magisterio le hiciese recordar alguna vez por simpatía la ejemplar vida de Bello; o pudo ser -simplemente-que sentía admiración singular por el maestro caraqueño; lo cierto es que Henríquez Ureña cebió leer y analizar muy bien los escritos de Bello; y como fruto de esos estudios nos han quedado dos de los más originales juicios que de la obra del sabio venezolano se han escrito; los cuales -además- tienen la particularidad de referirse, respectivamente, a asuntos tan disímiles como lo son la gramática y la poesía.

El primero de esos juicios lo escribe en una y otra de las dos obras que venimos mencionando. En "Las Corrientes literarias en la América Hispánica (texto de 1940-41, 1ra. edic. en inglés, 1945; en castellano, 1949$)^{3}$, hace un como descubrimiento, al señalar algo que ningún otro crítico bellista había hasta entonces advertido, a saber: que en América a la par con el movimiento de independencia política en el primer cuarto del siglo XIX, se había dado también el de independencia intelectual, cuya iniciativa fue emprendida por Bello. Leamos el texto de Henríquez Ureña: "El deseo de independencia intelec- 
tual se hace explícito por vez primera en la Alocución a la Poesía de Andrés Bello (1981-1º5), la primera de sus dos Silvas Americanas" "4.

Y en la "Historia de la Cultura en la América Hispánica"5, de aparecida manera escribe: "Dos odas (...) escribió el venezolano Andrés Bello (1781-1865) bajo el título de Silvas Americanas: la primera, Alocución a la Poesía (1823) contiene una declaración de independencia intelectual de la América española, comparable a la de Channing en su ensayo On National Literature (1823) y a la de Emerson en su discurso The American Scholar (1937) (... $)^{6}$.

Tan importante afirmación en la autorizada pluma de Henríquez Ureña ha corrido, desde su aparición, con la mejor buena suerte. Y así fue recordada y comentada singularmente al cumplirse en 1973 los ciento cincuenta años de la publicación de la referida silva de Bello. Ello nos ofreció ocasión para tratar de demostrar, en un ensayo que titulamos El letrado libertador, que una buena parte de la obra de Bello hasta 1823, probaba la afrmación hecha por Henríquez Ureña ${ }^{7}$.

No menos personal y nuevo fue el otro juicio; el referente a obra tan representativa de la cultura lingüística de Bello como su "Gramática de la Lengua Española". Con una concisión y una seguridad que suponen conocimiento previo muy preciso de lo que trata Henríquez Ureña sintetiza así su juicio respecto de aquella obra: "La Gramática de Bello sigue siendo, cumplidos los cien años, la más completa descripción sincrónica de nuestra lengua y una de las mejores de cualquier idioma moderno" 8 . Afirmación rotunda, elogio absoluto, que suenan muy gratamente a los oídos de cuantos estudiamos y admiramos la obra de cultura literaria del maestro caraqueño.

$Y$ resulta muy satisfactorio que ese juicio tan defeinitivo y preciso, además de novedoso en la forma como fue dicho, sea la expresión de ideas que aparecen con clara objetividad a los ojos de quien mira aquella obra de Bello con la seriedad y competencia necesarias para juzgarla debidamente.

Decimos esto, porque años después de haber escrito Henríquez Ureña el citado juicio. un buen amigo suyo español y 
colega en menesteres literarios y docentes en Buenos Aires, Amado Alonso (también de muy prematuro cuanto lamentado fallecimiento). fue encargado de escribir el estudio introductorio para la edición de la Gramática de Bello en la serie Obras Completas que se estaba publicando por el Ministerio de Educación de Venezuela.

Amado Alonso era en esos momentos uno de los filósofos de más alta reputación en el mundo de habla hispana. En esa especialidad, que no era precisamente la de Henríquez Ureña, podía esperarse -como de hecho sucedió-que Alonso escribiera un estudio que sería la última palabra en apreciación crítica de la obra gramatical de Bello. Se sabe que el autor tuvo mucho agrado al escribirlo e ilusión por verlo publicado sin duda para observar la complacencia con que dicho estudio sería recibido por los bellistas de todo el mundo. Infortunadamente, antes de que el volumen de la Gramática con el trabajo de Alonso saliera de las prensas, una terrible y rápida enfermedad cortó la laboriosa existencia del afamado filólogo español.

Sin duda -nos ocurre pensar-Henríquez Ureña y Amado Alonso en sus muchas horas de convivencia intelectual y docente, más de una vez debieron hablar de Bello y emitir opiniones y juicios que serían muy afines. Recuérdese que entre los dos habían compuesto y publicado en Buenos Aires un tratado, en dos cursos, de Gramática Castellana que tuvo muchas ediciones, y en cuya composición no es decible el número de veces que seguramente hubieron de acudir a la Gramática de Bello. El hecho es que, cuando años después de escrito el juicio de Henríquez Ureña que un poco antes hemos citado, acerca de la misma Gramática de Bello, le toca a Alonso escribir su propio estudio valorativo de dicha obra, lo concluye con las siguientes palabras: "Es una Gramática que ( . .) escrita hace más de cien años (. . .) se mantiene en pie como cosa bien viva. No como la mejor gramática a falta de otra, sino como una de las mejores gramáticas de los tiempos modernos en cualquier lengua" 
Bien advertirá el lector la manifiesta semejanza entre lo dicho al mismo respecto por uno y otro autor. Sus frases son agua de la misma fuente, y llevada - casi, casi- en el mismo cántaro. Se ve que Bello. bien estudiado, lleva a iguales conclusiones. Y también se ve que la fraternidad entre los dos comentaristas del viejo maestro, los llevó - aunque por caminos diversos- a tener que expresarse de tan parecida manera. Sin embargo. dado que el nombre de Amado Alonso era tan eminente en el campo de su especialidad como gramático, no podemos menos de encomiar el hecho de corresponderle a Henríquez Ureña el mérito de la primacía de juicio tan decisivo. Sin antecedente alguno impreso. y sin visible timidez, a riesgo propio, estampó ya en 1945 su claro y rotundo parecer acerca del mérito eminente de la Gramática de Bello. Ese juicio suyo había sido acertado. Seis años más tarde así lo confirma la autoridad de Amado Alonso. quien por modo tan coincidente vino a expresarse con palabras bien parecidas a las del escritor dominicano.

Nuestro anterior comentario no pretende. en manera alguna enfrentar méritos. Y menos entre nombres de quienes fueron en vida tan amigos y mutuo-colaboradores. Pero creímos que era oportuno señalar, en la coincidencia apuntada, aquello que evidentemente corresponde al sabio humanista dominicano: $\mathrm{y}$ que en el homenaje recordatorio que ahora se le rinde, tenga su pequeño lugar esta palabra que llega de la patria de Andrés Bello.

\section{NOTAS:}

1 Diez Canedo, Enrique, Letras de América, edic. El Colegio de México, 1944, p. 247.

7. Gómez Gil. Orlando, Historia Crítica de la Literatura Hispanoamericana. Holt, Rinehart and W inston, New York, 1968, p. 553.

3. Henríquez Ureña, Pedro, Las Corrientes Literarias en la América Hispánica, Fondo de Cultura Económica. México-Buenos Aires, 1949, p. 74.

4. Henríquez Ureña, Pedro, Ob cit. p 1 n3.

5. Henríquez Ureña. Pedro, Historia de la Cultura en la América Hispánica, Fondo de Cultura Económica. México-Buenoc Aires, 1949, p. 74. 
6 Henríquez Ureña, Pedro, Ob. cit.. ib.

7. Barnola, Pedro P., Afirmaciones de Cultura, Ediciones de la Presidencia de la República, Caracas 1973, cap I El letrado libertador, pp 9.42

$8 \quad$ Henr 1 quez Ureña, Pedro. Las Corrientes, Literarias, , p. 107.

9. Alonso, Amado, "Introducción a los Estudios Gramaticales de Andrés Bello", en: Bello, Andrés, Obras Completas, t. IV, Gramáticas, Caracas, 1951, p. LXXXVI. 